\title{
Study on Effectiveness of Yoga Training on Sustain Attention in Sub-groups of ADD, HD and ADHD Children
}

\author{
Zeynab Khanjani ${ }^{1}$, Mohammad Ali Nazari ${ }^{1}$, Ashraf Karami ${ }^{2}$ \\ ${ }^{1}$ Department of Psychology, Faculty of Education and Psychology, University of Tabriz, Tabriz, Iran \\ ${ }^{2}$ Department of General Psychology, Islamic Azad University of Tabriz, Tabriz, Iran
}

Email address:

ashraf_karamii@yahoo.com (A. Karami), zeynabkhanjani@yahoo.com (Z. Khanjani), nazaripsycho@yahoo.com (M. A. Nazari)

\section{To cite this article:}

Zeynab Khanjani, Mohammad Ali Nazari, Ashraf Karami. Study on Effectiveness of Yoga Training on Sustain Attention in Sub-groups of ADD, HD and ADHD Children. Psychology and Behavioral Sciences. Vol. 5, No. 4, 2016, pp. 77-82. doi: 10.11648/j.pbs.20160504.11

Received: May 26, 2016; Accepted: June 3, 2016; Published: June 20, 2016

\begin{abstract}
The aim of this study was to investigate the effects of Yoga on sustain attention in three groups of children with syndrome Attention - Deficit/ hyperactivity (ADHD), ADHD predominantly inattentive and ADHD predominantly hyperactivity. The number of 120 students (7-13 years old) with symptoms of ADHD were selected by Conner's teacher rating scale (CTRS), and parent rating- children symptom inventory (CSI-4), in common both forms, and were organized in two groups of Yoga and control. Continuous Performance Test (CPT) was done to evaluate sustain attention. Yoga group was given a 30-session course on Yoga training and control group, not. Then the same test was executed again on both groups as posttests. The result was analyzed by multivariable covariance analysis (MANCOVA). The results of this study indicate the efficiency of Yoga on increasing sustain attention in all sub-groups of children with symptoms of ADHD. Based on these findings, we concluded that Yoga can effect and help in attention improvement. Verification of such effects can be used to design effective non-drug therapies, such as effect of Yoga therapy on symptoms of ADHD.
\end{abstract}

Keywords: Sustain Attention, Yoga, Attention-Deficit / Hyperactivity Disorder (ADHD), ADHD Predominantly Inattentive, ADHD Predominantly Hyperactivity

\section{Introduction}

Among the variety of childhood disorders, Attention Deficit Hyperactivity Disorder (ADHD) is the most common disorder diagnosed during childhood. ADHD is a fixed pattern of inattention and hyperactivity. Currently, the diagnosis of ADHD is based on the consensus of experts, and three types of ADHD is visible: inattentive, hyperactive / impulsivity, or mixed. Evidence shows that 5 to 10 percent of children worldwide are affected by this disorder [12]. According to DSM-IV-TR, Symptoms must be presented in at least two areas such as home and school to fulfill the criteria for diagnosis of Attention Deficit Hyperactivity [25].

Symptoms of inattention in children with ADHD include errors caused by carelessness and Irregularity. In listening, following the instructions or assignments have attention center limitation and face to problem in long attention, are forgetful, they do not concentrate and are easily distracted during the activities. Diagnostic criteria for this disorder start before the age of seven and the symptoms last for 6 months [11].

Most children with ADHD have problems in realm of attention. Although the mechanism of this problem is still unknown, but some researchers emphasize on "distraction" as main criteria of disorder and some on "maintain attention" in these children [3]. Due to the disorder pathological background, emphasis on attention deficit component as fundamental failure, replaced with ADHD and then arousal component [11]. One of the greatest contemporary theoretical explanations knows the ADHD due to defects in executive function such as working memory and inhibition [4]. Barkley model is a scheme that triples system relations of inhibition, executive and motion functions are displayed in it and based on its components children with hyperactivity in each noted system suffer from failure and disorder, and the resultant of disorderliness in this triple system related to each other is occurrence of hyperactivity problem behavior, impulsivity and finally inattention. According to him, the most attention problem in children is sustained attention. Sustained attention 
helps persons to control other instigator and only responds to one instigator [4].

Although medications like consumption of Methylphenidate (Ritalin) are suitable to remove the disorder symptoms but not enough to learn new skills and not effective for all children and haven't long-term effect [11].

There are several methods to help increasing concentration and self-control in these children, including behavior modification techniques, behavioral approaches, parents' behavior management and etc., recently two methods of play therapy and yoga is considered in ADHD children [7].

According to researches has been performed on the effectiveness of yoga on self-regulation, behavioral control, reconstruction of behavior, balance effects, flexibility and strengthen of concentration power and relaxation [19], it seems that yoga could be effective in the goals of treatment. Flexibility, self-control and harness of concentration are a part of yoga training [10].

Yoga can also reduce the requirement for medicines for ADHD children $[13,26]$. In yoga practices, children on alert and controlled movements can learn restraint and supervision on movements and behavior [10]. Biophysiological data from Positron Emission Tomography (PET) and Quantitative Electroencephalography (QEEG) have demonstrated the effects of yogic breathing on cerebral lateralization [17], oxygen consumption and brain wave activity [16].

These changes are potential relevance to ADHD, where cerebral lateralization deficits and lower oxygen consumption [15]. Jensen \& Kenny (2004) reported a significant reduction in hyperactivity behaviors, after 20 sessions of yoga practices with a hyperactive boy [17]. Rangan et al. (2009) showed that curriculum with yoga practices can improve functioning of the right front parietal cortex which has mediating role in sustained attention [23].

Bhuyan (2004) showed the remarkable healing effects of yoga on concentration and attention of students [5]. Also a research in this field showed that yoga intervention and play therapy have same effect on reducing symptoms of ADHD in primary school students (9-12 years old) [24].

According to literature and lack of native researches in effect of yoga training in treatment of ADHD, current research try to investigate the effectiveness of yoga training on sustained attention and concentration in three groups of children with symptoms of combined ADHD, Inattentive ADHD and Hyperactive-Impulsive ADHD.

\section{Method}

\subsection{Statistical Population and Sample}

This study is case-control and pre-test post-test with control group. In this study yoga training in two level of training and control group (not-training) were considered as independent variable and focused attention (i.e. the correct answers, false declaration (commission) error and omission errors) considered as the dependent variable. The goal population was all boys and girls studying elementary in
Miyaneh city in year 2013-14.

Using multi-stage cluster screening method regarding 5$10 \%$ prevalence of children, sample size calculated 1536 persons. After running the CSI-4 test parents form and Conner's test teachers form, from the children who achieved the score higher than cutting line in hyperactivity sub-scale, 120 participants were selected among who were hyperactive in both form (parents and teachers) and didn't consume medicines such as Ritalin, and then divided in to three groups of combined ADHD, Inattentive ADHD and HyperactiveImpulsive ADHD. Then children randomly assigned to experimental and control groups (20 individuals in each group) (Table 1). Random replacement without synchronization used to select samples for two groups of experimental and control.

Table 1. Number of three studied groups in experimental and control sections.

\begin{tabular}{lll}
\hline Groups & Experimental group & Control group \\
\hline ADD & 20 & 20 \\
HD & 20 & 20 \\
ADHD & 20 & 20 \\
\hline
\end{tabular}

\subsection{Performance Method of Study}

A meeting held with parents to explain the yoga programs and justify the participants. Then pre-test administered by Continuous Performance Test (CPT) on subjects in all three groups (two experimental and control groups). Yoga training performed on the experimental groups for two days a week, for 15 weeks (total of 30 sessions). Running time for each yoga sessions was 70 minutes. After finishing the training sessions, posttest (CPT) performed on three groups in control and experimental groups and achieved data analyzed using MANCOVA multivariate covariance statistical analysis.

\subsection{Research Tools}

\subsubsection{Children Symptom Inventory (CSI-4)}

CSI is a behavior rating scale first introduced by Sprafkin and Gadow 1984 based on DSM-III classification and designed in order to screen 18 types of behavioral and emotional disorders in 5-12 years children. In 1987 DSMIIIR classification changed and revised with slight changes in 1994 in fourth publication of DSM-IV and finally called CSI4. The inventory includes two from of parents and teachers which is respond by four point Likert scale. CSI-4 has necessary validity and reliability to detect and identify children with emotional and behavioral disorder in clinical populations and high school. Sprafkin and Gadow calculated inventory validity from 0.7 to 0.8 and validity of this inventory in Iran for teachers from calculated 0.9 [18].

\subsubsection{Conners Teacher Rating Scale (CTRS)}

Conners Teacher Rating Scale includes two versions with 28 and 39 items which are supplementary of Conners parents' inventory. In this study a shortened version of Conners scale (28 items) applied which measures three 
domains of class behavior, participation in group and attitude to authority. Scoring the inventory is based on 4 point Likert scale from 0 to 3 . Conners reported retest reliability of teacher form during one month to one year from 0.72 to 0.92 and reliability grading of teachers was 0.7 . Cronbach's alpha coefficient for the questionnaire reported 0.61 to 0.95 .

\subsubsection{Continuous Performance Test (CPT)}

In this study CPT test was used to evaluate the sustained attention (continuous), this test applied to check the sustained attention, working memory and impulsivity.

There are different types of CPT test which Conners Type II applies in various disorders including ADHD, attention deficit, depression and disorders of the frontal cortex; also this type has high validity especially in ADHD and impulsivity [14]. Different forms of this test have been provided for therapeutic purposes so far and in this study the Persian version made and validated by [21] is applied. The test runs in computer and has 360 Persian numbers (1-9) as stimulant, which 90 percent are target stimulant and 10 percent as non-target stimulus. Test reliability coefficients in various indices calculated in the range of $0.45-0.77$. Criterion validity was performed by comparing normal groups with $\mathrm{ADH}$ group using $\mathrm{T}$ test and showed a significant difference between two groups [21].

\subsection{Yoga Training Package}

This package designed for 30 sessions and the content of each yoga session for children was as follows:

- Breath exercises (pranayama)

- Mobility exercises (asana)

- Body relaxation and visualization of the beach, desert, forest and space

- Meditation with candles for 10 minutes at the end of session

- And after the end of each session children received a leaf mandala painting as assignment.

Breathing exercises (pranayama) including: full breathing, breathing off the five candles, deep breathing "HAA", periodic breathing, blowing the feathers and ping-pong ball and the woodcutter. Motion physical exercises (asana) include: standing exercises: mountain, triangle, warrior, archer, chest expansion, balance movements, trees, folded leaves, angel, and boat. Torsional movements: waist spins, twisting the spine, triangle spin, rainbow spin. Stretching: camel, cobra, swan, bow, lifting the sides, Swing, folded leaves, head of cow, back stretch, pectoral stretch, clasp hands from back. Sitting exercises: cat, balance cat, tiger, rabbit, praying, lion, baby, butterfly, half lotus. Upside down exercises: dog, legs to the wall (with candles), simple bridge. Cyclical movements: Sun Salutation pose (Hi to sun). Successive movements: flamingoes and toward peace at night.

\subsection{Content of Training Sessions}

Session 1: Acquaintance and relationships with participants, explanation about performance of the exercises, warming up, full breathing, mountain, triangle, tree, angel, twisting the spine, stretching back, cats, half butterfly and relaxation.

Session 2: warming up, honeycomb breathing, mountain, warrior, tree, boat, rotating the waist, chest expansion, Cobra, half lotus, rabbits, relaxation and visualization imaginary.

Session 3: warming up, deep breathing, triangle, angel, boat, rotating the waist, triangle spin, back stretch, swing, Cobra, balance, cats, rabbits, baby, body relaxation and visualization, meditation with candle.

Learning new exercises and movements completed in the 12 sessions and repeated in the rest of sessions.

\subsection{Multivariate Analysis of Covariance (MANCOVA)}

MANCOVA is an extension of analysis of covariance (ANCOVA) methods to cover cases where there is more than one dependent variable and where the control of concomitant continuous independent variables - covariates - is required. Dependent variable of current study is sustain attention and covariates are Correct Answers, Commission Error and Omission Error. Yoga training in trained and control groups is independent factor.

\section{Results}

Before examining multivariate analysis of covariance analyze and report on the Continuous Performance Test (CPT), in each of the three types of disorder, ADD, HD and ADHD meet the assumptions of the analysis show that the data had a normal distribution and there is no interaction between independent variables and confounding variable. In other words, the data homogeneity supports the slopes of the regression. Levene test indicates a non-significant result which shows the compliance of error variances equality condition. Thus, according to assumption of covariance analysis compliance, the dependent variables were compared to experimental and control groups. Based on results of Tables 2, 3 and 4 in CPT Test, the Wilks Lambda is measured 0.33, 0.69 and 0.605 in ADD, HD and ADHD disorder respectively and statistically significant in levels of 0.001 , 0.005 and 0.05 respectively. This suggests that there is a significant difference at least in one of the dependent variables i.e. correct answers, commission error, omission errors significant between experimental and control groups. Therefore the variables and their impact on yoga training were discussed separately.

The findings of Tables 2, 3 and 4 in sub-scales of CPT Test in disorders of $\mathrm{ADD}, \mathrm{HD}$ and $\mathrm{ADHD}$ for both groups of experimental and control in level of 0.05 for three dependent variable of correct answers, commission error and omission errors in pre-test are similar and in post-test are significant. This shows that among ADHD students, those who participated in yoga training sessions have fewer omission error and commission error compared with students who didn't participate in yoga training sessions and have more correct answers. 
Table 2. Results of MANCOVA for pre-test and post-test average scores of experimental and control groups in the domain of CPT test in ADD disorder.

\begin{tabular}{|c|c|c|c|c|c|c|c|c|}
\hline & & \multicolumn{2}{|c|}{ Control Group } & \multicolumn{4}{|c|}{ Experimental Group } & \multirow[b]{2}{*}{ Significant level } \\
\hline & & Mean & Standard deviation & Mean & Standard deviation & $\mathbf{F}$ & Degree of freedom & \\
\hline \multirow{2}{*}{ Correct Answers } & Pre-test & 308.56 & 17.55 & 299.1 & 14.56 & 3.29 & 19 & 0.08 \\
\hline & Post-test & 304.89 & 15.17 & 314.05 & 10.73 & 4.69 & 19 & 0.04 \\
\hline \multirow{2}{*}{ Commission Error } & Pre-test & 21.06 & 6.19 & 17.45 & 8.83 & 2.08 & 19 & 0.16 \\
\hline & Post-test & 20.94 & 7.32 & 9.85 & 5.95 & 26.51 & 19 & 0.00 \\
\hline Omission Error & Pre-test & 11.33 & 13.97 & 18.4 & 10.25 & 3.2 & 19 & 0.082 \\
\hline
\end{tabular}

Table 3. Results of MANCOVA for pre-test and post-test average scores of experimental and control groups in the domain of CPT test in HD disorder.

\begin{tabular}{|c|c|c|c|c|c|c|c|c|}
\hline & & \multicolumn{2}{|c|}{ Control Group } & \multicolumn{3}{|c|}{ Experimental Group } & \multirow[b]{2}{*}{ Degree of freedom } & \multirow[b]{2}{*}{ Significant level } \\
\hline & & Mean & Standard deviation & Mean & Standard deviation & $\mathbf{F}$ & & \\
\hline \multirow{2}{*}{ Correct Answers } & Pre-test & 293.55 & 25.05 & 284.75 & 33.12 & 0.9 & 19 & 0.35 \\
\hline & Post-test & 286.65 & 26.07 & 308.55 & 16.4 & 10.11 & 19 & 0.00 \\
\hline \multirow{2}{*}{ Commission Error } & Pre-test & 17.1 & 6.05 & 17.75 & 6.81 & 0.1 & 19 & 0.75 \\
\hline & Post-test & 14.65 & 7.89 & 10.2 & 6.84 & 3.63 & 19 & 0.045 \\
\hline \multirow{2}{*}{ Omission Error } & Pre-test & 13.3 & 8.12 & 17.2 & 10.25 & 1.78 & 19 & 0.19 \\
\hline & Post-test & 8.85 & 8.24 & 11 & 5.53 & 2.52 & 19 & 0.048 \\
\hline
\end{tabular}

Table 4. Results of MANCOVA for pre-test and post-test average scores of experimental and control groups in the domain of CPT test in ADHD disorder.

\begin{tabular}{|c|c|c|c|c|c|c|c|c|}
\hline & & \multicolumn{2}{|c|}{ Control Group } & \multicolumn{4}{|c|}{ Experimental Group } & \multirow[b]{2}{*}{ Significant level } \\
\hline & & Mean & Standard deviation & Mean & Standard deviation & $\mathbf{F}$ & Degree of freedom & \\
\hline \multirow{2}{*}{ Correct Answers } & Pre-test & 259.9 & 26.46 & 280.15 & 34.79 & 2.6 & 19 & 0.12 \\
\hline & Post-test & 295.1 & 20.13 & 310 & 13.17 & 7.62 & 19 & 0.01 \\
\hline \multirow{2}{*}{ Commission Error } & Pre-test & 20 & 7.43 & 21.85 & 7.53 & 0.61 & 19 & 0.44 \\
\hline & Post-test & 18.95 & 7.72 & 13.45 & 8.06 & 4.86 & 19 & 0.03 \\
\hline \multirow{2}{*}{ Omission Error } & Pre-test & 12.55 & 17 & 39.15 & 35.29 & 9.22 & 19 & 0.00 \\
\hline & Post-test & 13.45 & 12.38 & 11.8 & 5.86 & 2.19 & 19 & 0.043 \\
\hline
\end{tabular}

\section{Discussion and Conclusions}

The result of this study revealed that Yoga training has significant effect in focused attention (sustain attention) of children with ADHD syndrome in three groups with the emphasis on attention deficit, hyperactivity and kind stressed compound. Yoga participants are significantly better than control group regarding to correct answers, omission errors and CPT indicators. Scores of experimental group was significantly higher than the control group in all aspects of attention. The correct answers for the groups of mainly inattentive, predominantly hyperactive and combined type represent a significant increase in Yoga practitioners. Also the omission error indicator for all three groups was highly significant. These findings are consistent with findings of [23] which showed that yogic education system of modern education system was more effective on sustained attention; and their subjects were normal children. Also the current research is consistent with the findings of Jensen and Kenny (2004) was conducted on children with ADHD, indicating the effectiveness of Yoga. The alignment of [24] in Yoga training on elementary school students (9-12 years old) who had initial diagnosis of ADHD is consistent with current study. In addition, the results of [1] research on patients with ADHD did Yoga exercises; Yoga practitioners show improvement compared to the group was participating in group activities. Yoga group members, in addition to the presence in Yoga sessions of those who practiced Yoga sessions at home also showed greater improvement in behavior and attention and this is quite consistent with the findings of the present study were those who had regular attendance at classes and at home were practicing, recovery was very impressive. Also current research is consistent with [27]. They emphasized the effects of breathing in Yoga practice is one of the components, on sustain attention, selective attention and the ability to change the test subjects were given and the results were statistically significant. The findings of a study [5] efficacy of Yoga in dramatic improvements in attention and concentration showed that current research findings can be confirmed. A study [6] using the scale diagnosis of ADHD Vanderbilt, teacher form revealed dramatic changes positively in all participants in curriculum-based Yoga, and in all subscales of Vanderbilt that herald the impact of Yoga exercises in concentration and reduce distraction and confusion in class. Yoga by controlling the inhale (the soul) and deep relaxation, self-control, raises the attention and concentration. All researches that used Yoga and its supplements (meditation, breathing exercises, etc.) in conjunction with attention problems and have reached the desired results, can be used as further evidence that Yoga and related practices it can cause the brain to improve attention and functions [20].

In general, the results of this study indicate the efficiency of Yoga on increasing focused attention in all sub-groups of children with symptoms of ADHD. Chabildas et al. (2001) and Brown (2006) confirmed these findings [8,9], which in their studies showed that there is no difference between the 
sub-groups of ADHD in terms of executive functions, due to their similar profiles, it seems that the effect of the treatment for all ADHD subtypes are the same. Also in O'Driscoll's study [22] results showed that consumption of methylphenidate can reduce ADHD symptoms of all groups. Meanwhile, the Barkley et al (1992) showed that HD + AD Group act as ADD Group on tests of frontal lobe and it appears that there is a similar neural structure for both subgroups; therefore there will be equal efficiency in ADHD treatment [2]. Based on these findings, we concluded that Yoga can effect and help in attention improvement. Verification of such effects can be used to design effective non-drug therapies, such as effect of Yoga therapy on symptoms of ADHD.

The most important limitation of this paper is that this research is conducted on the subject of 13-7 year-old age group (primary school) with ADHD symptoms which reduce its generalization to other age groups and child disorders such as learning, ODD and etc. It is suggested that yoga training effects evaluate on other executive functions variables and checked in other ages and other disorders. Also in schools, yoga training programs should be provided for students in order to increase focus and efficiency of brain functions and provide academic progress and reducing inattention and control impulses and fostering social aspects and other benefits. All educational institutions, schools, kindergartens, special schools, clinics, psychology and rehabilitation centers can use this therapy to relief the symptoms of ADHD.

\section{References}

[1] Archer, Shirley (2004), Yoga may help kids with ADHD. Journal of Attention Disorder, 7 (4): 205-16.

[2] Barkley, R. A., Grodzinsky. G., \& DuPaul, G. J. (1992), Frontal lobe functions in attention deficit disorder with and without hyperactivity as defined by research criteria. Journal of Consulting and Clinical Psychology, 58: 775-789.

[3] Barkley, R. (1993), Developmental Psychopathology, translated in Persian by Dadsetan, P. (2009). Volume II, Samt Pub. Tehran.

[4] Barkley, R. A. (1997), Behavioral Inhibition, Sustained Attention and Executive Function: constructing a unifying theory of ADHD. Psychological Bulletin, 121 (1): 65-94.

[5] Bhuyan, B. (2004), Comparative study of three different Yoga modules on Attention and Concentration in normal children (9-12 years), Master's Thesis in Yogic Sciences. A deemed University, Recognised by UGC, Ministry of HRD, Govt. of India.

[6] Boeshansz, Marjorie, M. ED. (2009), The effect of curriculum based Yogaon Children with attention deficit/hyperactivity disorder. Master's thesis in Education. College of Education Ohio University, USA.

[7] Bray, M. A. Kehle, T. J. Peck, H. L. \& Theodore, L. A (2005), Yoga as anintervention for children with attention problems. School Psychology Review, 34 (3): 415-424.
[8] Brown, T. E. (2006), Executive function and attention deficit hyperactivity disorder: implication of tow conflicting views. International journal of disability, Development and education, 53 (1): 35-46.

[9] Chabildas, Nomita, Pennigton, Bruce F., Willcutt \& Erik. G. (2001), A comparison of the Neuropsychlogical profiles of the DSM-IV subtype of ADHD. Journal of abnormal child psychology, 29 (6): 529-540.

[10] Cheesebrough, M. Woodhouse, S. \& Griffiths R. (2006), Helping children with Yoga: a guide for parents and teachers, translated in Persian by Ghasemi nezhad, B. (2010). Fararvan Pub. Tehran.

[11] Conners, C. \& Jett, J. (1996), Attention deficit/hyperactivity disorder (in adults and children), translated in Persian by Mirnasab, M. \& Arjmand, M. (2010). Arjmand Pub. Tehran.

[12] Faraon, S. Sergeant, J. Gillberg \& C. Biederman, J. (2003), The worldwide prevalence of ADHD: Is it American condition? World Psychiatry, 2: 104-113.

[13] Flisek, L. (2001). Teaching Yoga to young school children. Positive Health, 70: 50-54.

[14] Hadianfar, H. Najjarian, B. Shekarkan, H. \& Mehrabi-zadeh, M. (2000), Procurement and construction Persian form of continuous performance test, Journal of Psychology, 2 (4): $388-440$.

[15] Hillman, K. M. Voeller, K. K. \& Nadeau, S. E. (1991), A possible pathophysiologic substrate of attention deficit hyperactivity disorder. Journal of Child Neurology, 6: 76-81.

[16] Hoffman, E. (1999), Mapping the brain waves after Kriya Yoga. Bindu, 12, Haa Course Venter: Sweden.

[17] Jensen, P. S. \& Kenny, D. T. (2004), The effects of Yoga on the attention and behavior of body with attention deficithyperactivity disorder (ADHD). Journal of Attention Disorder, 7: 205-216.

[18] Mohammad Ismail, E. \& Alipour, A. (2001), Study on reliability, validity and determination of cut-off points disorder Child Symptom Inventory (CSI-4) on the 6-14 years old students in elementary and secondary schools in Tehran, Institute of exceptional children, Tehran.

[19] Moliterno, M. (2008), Yoga Voice: Balancing the physical instrument. Journal of singing, 65 (1): 45-52.

[20] Moore, A. \& Malinowski, P. (2009), Meditation, mindfulness and cognitive flexibility. Consciousness and Cognition, 18 (2009): 176-186.

[21] Nazari, M. A. Mirloo, M. M. \& Asadzadeh, S. (2011), Time perceptual error in the processing of emotional Persian words. Journal of Cognitive Science News, 13 (4): 37-48.

[22] O'Driscoll, G. A. De'patie, L. Holahan, A. L. savion, T. S. Barr, R. G. Jolicoeur, C. \& Douglas, V. (2005), Executive Function and Methylphenidate Response in Subtypes of Attention-Deficit/Hyperactivity Disorder. Biol Psychiatry, 57: 1452-1460.

[23] Rangan, R. Nagendra, H. R. \& Ramachandra B. (2009), Effect of yogic education system and modern education system on sustained attention. International Journal of Yoga, 2 (1): 3538 . 
[24] Saa'dat, M. (2011), Which symptoms of attention deficit/hyperactivity will change by intervention of play therapy and Yoga? Journal of Exceptional Children, 11 (1): 45-56.

[25] Sadock, B. \& Sadock, V. (2009), Comprehensive Textbook of Psychiatry, Translated in Persian by Pour Afkari, N. A. 2011. Volume III, Shahre Ab Pub. Tehran.
[26] Santangelo W. L. (2009), Yoga for children. Pediatric Nursing, 35 (5): 277-295.

[27] Telles, S. Raghuraj, P. Arankalle, D. \& Naveen. K. V. (2008), Immediate Effect of high-frequency Yoga breathing on attention. Indian J Med Sci, 62 (1): 20-22. 